\title{
The Influence of Wood and Basalt Fibres on Mechanical, Thermal and Hydrothermal Properties of PLA Composites
}

\author{
Stanisław Kuciel ${ }^{1}$ D $\cdot$ Karolina Mazur $^{1} \cdot$ Marek Hebda $^{1}$
}

Published online: 14 February 2020

(c) The Author(s) 2020

\begin{abstract}
In this study, biodegradable biocomposites based on polylactide with basalt fibres (BFs) or wood fibres (WFs) of 7.5 or 15 $\mathrm{wt} \%$ were prepared by injection moulding. Various tests, including tensile test, bending test and impact test, were carried out to investigate the mechanical properties of the composites. Additionally, the samples were tested at different temperatures. Depending on the type of fibre, differences were noted in their mechanical properties; the addition of WF caused a decrease in strength and the higher the fibre content, the higher the decrease was noted from $18 \%$ up $25 \%$ in the case of tensile strength. However, the Young modulus was improved by $45 \%$ for composites with $15 \mathrm{wt} \%$ of WF. The addition of BF improved all the properties, especially Young modulus was improved by over $45 \%$. Despite the low strength observed in neat polylactide at high temperatures-394 MPa, the addition of WF or BF improved the flexural strength more than twofold up to $1684 \mathrm{MPa}$ (PLA/15BF). Moreover, the addition of natural fibres caused an increase in dimensional stability as shown by the decrease of the coefficient of thermal expansion which dropped over $50 \%$ for composites with $15 \mathrm{wt} \%$ of BF, which significantly expands the areas of use of materials. After 4 weeks of biodegradation, only a slight decrease approximately $5 \%$ was observed in the mechanical properties together with an increase in crystallinity. Overall, the results confirm that the prepared composites can be successfully used in engineering applications with long-term operation.
\end{abstract}

Keywords Basalt fibre $\cdot$ Wood fibre $\cdot$ Mechanical properties $\cdot$ Biocomposites

\section{Introduction}

Currently, polymer composites are widely available on the global market, and the number of products made of polymer composites is increasing every year. In 1950, 2.3 million tonnes of polymer composites were produced, and by 2018 , the total production of polymer composites reached 6.3 billion tonnes, of which only $9 \%$ were recycled and $12 \%$ were combusted [1]. Researchers have estimated that by 2050 the number of polymer composites produced will be doubled, resulting in a significant increase in waste and posing a real threat to the environment. Therefore, biodegradable and compostable materials are increasingly introduced to the global market to minimise the effects of littering on the environment. Biodegradable polymer composites have similar mechanical properties as petrochemicals; however, they

Stanisław Kuciel

stask@mech.pk.edu.pl

1 Faculty of Materials Science and Physics, Cracow University of Technology, Warszawska 24, 31-155 Krakow, Poland differ in the ability to undergo biodegradation. Biodegradation is a process in which under appropriate conditions a material decomposes into biomass, water and $\mathrm{CO}_{2} / \mathrm{CH}_{4}$ (depending on the amount of oxygen). This means that after the end of their life cycle, the products made of biodegradable polymers decompose in a short time into products that naturally occur in the environment. The most commonly known biodegradable polymer is polylactide (PLA) [2]. It is produced from natural resources and is therefore completely compostable. PLA is characterised by good stiffness and strength, potential biodegradability and low energy requirement for production. Despite these qualities, PLA has some important limitations affecting its large-scale production, such as brittleness due to glass transition $\left(\mathrm{T}_{\mathrm{g}} 55-60{ }^{\circ} \mathrm{C}\right)$, low thermal stability, low toughness and low impact strength [3, 4]. PLA is usually considered as a material that can be used in medicinal applications. Some of the PLA-based products used in medicine are dressing (including hydrogel), resorbable surgical sutures, bone implants and connectors and screws for fixing broken bones [5]. The products made of PLA are mostly used in the packaging and textile industries. 
However, due to the high strength and stiffness, PLA can also be used in for both short- and long-term applications, such as in the manufacturing of garden furniture, and in the automotive, electronic and aerospace industries [6].

To overcome the aforementioned disadvantages and to expand the possibilities of use, PLA is often modified, for example, by forming blends with other polymers or by adding a plasticiser or other fillers (fibres). In the case of biodegradable materials, to increase the possibilities of use in the engineering industry, they are reinforced with natural fibres to maintain their renewable nature and biodegradability. The most common natural filler is wood which is used in all its forms (e.g. WF and wood flour (WFl)) due to its low price, easy availability and bio-based nature [7]. Typical wood plastic composites (WPCs) are based on polyvinyl chloride, polypropylene (PP), polyethylene, etc. [8, 9]. Studies on polymer composites reinforced with wood are increasingly found in the literature; in particular, biodegradable polymers such as PLA are used as matrix [10, 11]. The addition of WF increases the stiffness of polymer composites, exerts a minimal effect on density and enhances the cost-effectiveness of the finished product. Unfortunately, WFs also exhibit some disadvantages such as heat or water sensitivity and poor adhesion due to their high hydroscopic nature in comparison with the hydrophobic polyolefin matrices. Furthermore, the addition of natural fillers makes the manufacturing process difficult because natural fillers, mainly those containing lignocelluloses, are thermally sensitive components [12]. Due to the disadvantages associated with WPC processing, composites are produced with mineral fillers $[13,14]$. Not only the addition of mineral fillers results in a significant increase in strength, but it also makes the material environment-friendly. One of the mineral fillers that are now gaining popularity is basalt. Basalt is a common volcanic rock formed from the rapid cooling lava, which is virtually present everywhere in the world. It is a natural and thermally stable material and exhibits excellent chemical resistance in a corrosive environment. Moreover, it has a well-developed fibre surface that facilitates better interaction between the fibres and the matrix. All these features make BFs comparable with or even better than glass fibres and carbon fibres which are considered as the most reliable polymer additives [15]. Many studies have shown that the addition of $\mathrm{BF}$ renders the composites with higher mechanical and thermal properties [16].

From the scientific point of view, it is evident that there is a lack of knowledge about the mechanical properties of PLA composites reinforced with natural fibres and their performance at lowered and elevated temperatures. The performance tests are usually carried out at room temperature, but composites with good mechanical properties can be successfully used in the industries where temperatures ranging from -40 to $125^{\circ} \mathrm{C}$ are applied [17].
The main objective of this study was to compare the properties of biodegradable composites prepared with additives of different origins. According to the literature, natural additives act as excellent reinforcing fillers; however, a comprehensive comparative analysis of natural fillers from various sources has not been carried out so far. Therefore, in this study, composites based on PLA were prepared by injection moulding with various types of fibres (WF or BF) added at different contents ( 7.5 or $15 \mathrm{wt} \%$ ). The mechanical properties, including tensile strength $\left(\sigma_{t}\right)$, modulus of elasticity $\left(\mathrm{E}_{\mathrm{t}}\right)$ and strain at break $\left(\varepsilon_{\mathrm{B}}\right)$, as well as flexural modulus $\left(\mathrm{E}_{\mathrm{f}}\right)$ and flexural strength $\left(\sigma_{\mathrm{f}}\right)$ and impact strength $\left(\mathrm{a}_{\mathrm{cU}}\right)$ at room temperature and additionally at -24 and $80^{\circ} \mathrm{C}$, were evaluated. Furthermore, the mechanical properties of the tested materials after hydrolytic degradation in saline solution at $40{ }^{\circ} \mathrm{C}$ were investigated. The relationship between the mechanical properties and thermal properties of the samples after injection and hydrolytic degradation was analysed by differential scanning calorimetry (DSC). Scanning electron microscopy (SEM) analysis was also performed to assess the distribution of particles and the adhesion of the fillers to the matrix.

\section{Materials and Methods}

\section{Materials and Composites Preparation}

PLA (trade name PLI003) obtained from Nature Plast (France) in pallet form was used as a matrix for composites. The characteristics of PLA were: density $1.24 \mathrm{~g} / \mathrm{cm}^{3}$, fluidity index $190{ }^{\circ} \mathrm{C} / 2.16 \mathrm{~kg} 35 \mathrm{~g} / 10 \mathrm{~min}$, tensile modulus $3500 \mathrm{MPa}$, Charpy impact test (without notch) $16 \mathrm{~kJ} / \mathrm{m}^{2}$ and thermal resistance (HDT B) $55^{\circ} \mathrm{C}$. The following additives were used in the preparation of composites:

- WFs (LignocelC120) with a length of 70-150 $\mu \mathrm{m}$ provided by JRS Rettenmaier \& Soehne GmbH (Rosenberg, Germany) and

- BFs (basalt chopped standard 17-6.4-KV16) with a length of $6.35 \mathrm{~mm}$ and a diameter of $17 \mu \mathrm{m}$ provided by Basaltex Inc. (Belgium).

PLA composites with a WF content of 7.5 or $15 \mathrm{wt} \%$ (PLA/7.5W and PLA/15W) and PLA composites with the same content of BF (PLA/7.5B and PLA/15B) were prepared. Unmodified PLA polymer was used as a reference sample. The composition of the composites was determined based on previous studies, and by reviewing the literature where it is shown that a high amount of fillers hinders the preparation process and the introduction of $\mathrm{BF}$ into the polymer matrix at an amount of $>20 \mathrm{wt} \%$ does not cause a significant reinforcement [18]. WF and BF were compounded with PLA using a co-rotating twin-screw extruder 
(Maris America Corp., Windsor Mill, MD, USA). Standard dumbbell samples meeting the norm of PN-EN ISO 3167 (diameter $30 \mathrm{~mm}, \mathrm{~L} / \mathrm{D}=25 \mathrm{screw}$ ), manufactured using the Engel ES 200/40 HSL injection moulding machine by Grupa Azoty (Tarnow), were used. The parameters of the injection process were the same for all the tested materials-drying temperature: $80{ }^{\circ} \mathrm{C}$, drying time: $2-3 \mathrm{~h}$ to reduce moisture to $0.025 \%$, mould temperature: $15-35{ }^{\circ} \mathrm{C}$, feed zone temperature: $20-40{ }^{\circ} \mathrm{C}$, zone 1 temperature: $150-160{ }^{\circ} \mathrm{C}$, zone 2 temperature: $160-170{ }^{\circ} \mathrm{C}$, zone 3 temperature: $170-180^{\circ} \mathrm{C}$, nozzle temperature: $180-200^{\circ} \mathrm{C}$, screw speed: $100-175 \mathrm{rpm}$ and back-pressure: $950-1800$ bar.

\section{Characterization}

\section{Morphological Analysis}

The characteristics of each type of fibre in the matrix, the distributions of fibres and the deformation mechanism of composites were studied using a scanning electron microscope (JEOLJSM5510LV,Tokyo, Japan) in low-vacuum made on tensile-tested fracture-surfaced specimens. The specimens were gold-sputtered before analysis using an auto vacuum coater (Cressington, Watford, UK) to increase the local electrical conductivity.

\section{Density}

The density $(\rho)$ of the samples was determined using the RADWAG WAS 220/X (Radom, Poland) electronic analytical balance following the immersion method according to the PN-EN 1936 standard. Five measurements were taken for each composite to obtain an average value and calculate the relative standard deviation.

\section{Charpy Impact Test}

Charpy impact test was carried out in accordance with the PN-EN ISO 179-2 standard using the Zwick/Roell MTS-SP testing machine (Ulm, Germany). The impact energy of $1.5 \mathrm{~J}$ was applied for the un-notched samples. An average value of the un-notched impact strength $\left(\mathrm{a}_{\mathrm{cU}}\right)$ was calculated from five measurements.

\section{Vicat Softening Temperature}

Vicat softening temperature (VST) was determined using Ceast HDT and Vicat Tester Type 6520 (Pianezza, Italy). Samples were placed in an oil bath in accordance with the ASTM-D1525 standard. VST was measured with 5-N load at a heating rate of $50{ }^{\circ} \mathrm{C}$ per hour.

\section{Coefficient of Thermal Expansion}

The thermal properties of composites were determined from the coefficient of thermal expansion (CTE) and the results of the DSC analysis. CTE was examined using the NETZSCH 402 F1 Hyperion device (Selb, Germany) with Proteus software (ver. 5.2). The composite samples were placed vertically in the device, and were first cooled from 23 to $-30{ }^{\circ} \mathrm{C}$ and then heated up to $130{ }^{\circ} \mathrm{C}$ and again cooled down to $-30{ }^{\circ} \mathrm{C}$ at a rate of $10^{\circ} \mathrm{C} / \mathrm{min}$. To calculate the coefficient of linear thermal expansion $\left(\alpha_{\mathrm{L}}\right)$, the following formula was used:

$\propto_{L}=\frac{1}{L_{0}} \frac{\mathrm{d} L}{\mathrm{~d} T}, 1 / K$

where $L_{0}$ is the initial dimension of the sample, and $\mathrm{d} L$ and $\mathrm{d} T$ are the first derivative of the dimension and temperature, respectively.

\section{Differential Scanning Calorimetry}

DSC was performed using the Mettler Toledo DSC1 device (Columbus, USA). The analysis was carried out on samples weighing 7.27-7.77 mg, obtained from the head of the dumbbell samples. The measurements were taken under argon atmosphere $(30 \mathrm{ml} / \mathrm{min})$ according to the following procedure: heating from 25 to $200{ }^{\circ} \mathrm{C}$ at a rate of $10{ }^{\circ} \mathrm{C} / \mathrm{min}$, resting at $200{ }^{\circ} \mathrm{C}$ for $2 \mathrm{~min}$ and then cooling down to $25^{\circ} \mathrm{C}$ at a rate of $10{ }^{\circ} \mathrm{C} / \mathrm{min}$. The whole process was carried out twice to eliminate the processing memory/ history of the materials (the first heating-cooling cycle) and thermal properties of the composites (the second heating-cooling cycle). An empty pan was used as a reference. The degree of crystallisation was calculated based on the following formula, with a theoretical enthalpy of fusion of $100 \%$ crystalline PLA at $93.0 \mathrm{~J} / \mathrm{g}$ [19]:

$X_{\mathrm{c}}=\left[\frac{\Delta H_{\mathrm{m}}-\Delta H_{\mathrm{cc}}}{\Delta H_{\mathrm{mPLA}} \times(1-\alpha)}\right] \times 100$

where $X_{\mathrm{c}}$ is the degree of crystallisation [\%], $\Delta H_{\mathrm{m}}$ is the melting enthalpy $(\mathrm{J} / \mathrm{g}),-\Delta H_{\mathrm{cc}}$ is the cold crystallisation enthalpy $(\mathrm{J} / \mathrm{g}), \Delta H_{\mathrm{mPLA}}$ is the melting enthalpy of $100 \%$ crystalline PLA $(\mathrm{J} / \mathrm{g})$ and $\alpha$ is the mass fraction of fibres.

\section{Tensile Test}

The tensile test was performed at a constant crosshead speed of $5 \mathrm{~mm} / \mathrm{min}$, and the elongation was evaluated using the MTS axial extensometer with crosshead displacement. The tensile strength $\left(\sigma_{t}\right)$, modulus of elasticity 
$\left(\mathrm{E}_{\mathrm{t}}\right)$ and strain at break $\left(\varepsilon_{\mathrm{B}}\right)$ were determined in the test according to the PN-EN ISO 527-1:1998 standard.

\section{Flexural Test}

The flexural strength $\left(\sigma_{f}\right)$ and modulus $\left(\mathrm{E}_{\mathrm{f}}\right)$ were determined using a three-point bending test at a crosshead rate of $5 \mathrm{~mm} /$ min according to the PN-EN ISO 178 standard.

All mechanical tests were performed at room temperature and a relative humidity of $60 \%$. Additionally, the tests were carried out at two temperatures: (i) $-24{ }^{\circ} \mathrm{C}$ by keeping the specimens in the fridge (Samsung AZ8) and (ii) $80^{\circ} \mathrm{C}$ after heating the specimens in the temperature chamber (Instron). The specimens were conditioned at the testing temperature for $30 \mathrm{~min}$ before the tests. The values of the lowest and elevated temperatures reflected the lowest and highest temperatures at which PLA can be potentially used, respectively. The mechanical properties of PLA were studied using the universal MTS Criterion Model 43 testing machine. The measurements were taken from an average of at least 10 specimens for each composite in tensile and bending tests.

\section{Water Uptake}

Water absorption during hydrolytic degradation was measured according to the PN-EN ISO 62:2000 standard. Briefly, samples were immersed in distilled water mixed with salt (2\%) like physiological saline and maintained at $40{ }^{\circ} \mathrm{C}$ for 1,7 and 28 days. Then, they were dried and weighted with an accuracy of $0.0001 \mathrm{~g}$ using the RADWAG WAS 220/X electronic analytical balance. The measurement was taken three times for each sample. Finally, water uptake was calculated as the mass difference, expressed in percentage, using the following formula (3):
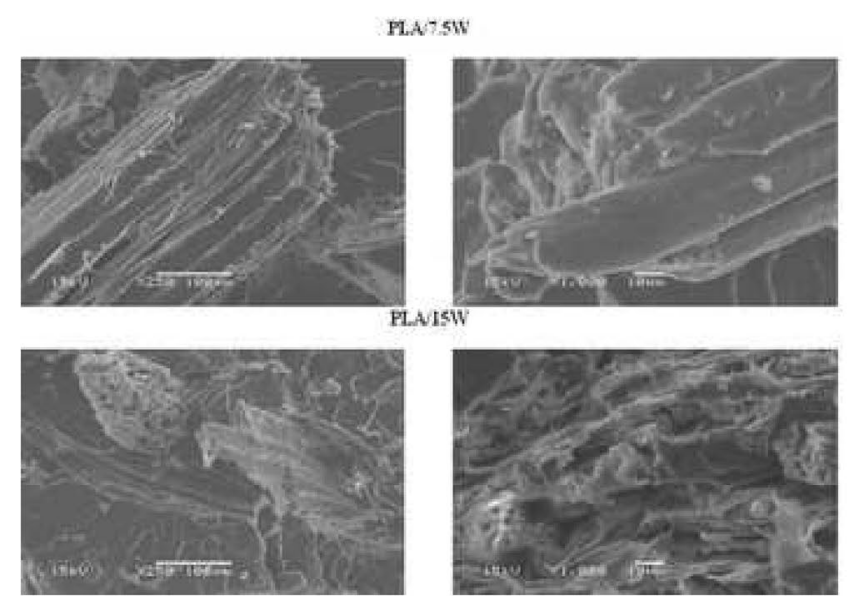

$M_{\mathrm{t}}=\left[\frac{W_{\mathrm{t}}-W_{0}}{W_{0}}\right] \times 100$

where $\mathrm{M}_{t}$ stands for the percentage of water content, $\mathrm{W}_{t}$ for the instantaneous weight of the sample and $\mathrm{W}_{0}$ for the initial weight of the sample.

To determine the influence of water uptake on the basic mechanical properties of the specimens which were incubated for 28 days in water, a tensile test was performed.

\section{Results and Discussion}

\section{Microstructure}

In Fig. 1 was presented SEM microstructures where can be seen a uniform distribution of wood and basalt fibres in the polymer matrix proportional to the amount of introduced filler. Breakthroughs were characterised by brittle fracture, which is the observed phenomenon after the introduction of natural fibres into the matrix. No visible agglomerations for both WF and BF were observed. The differences in the morphological structure of fibres are visible in the SEM microstructures. The WF consist of several microfibrils, which makes that they have a much more developed surface area than BF. BF is characterised by a high length of about $200 \mu \mathrm{m}$ and a small diameter of $17 \mu \mathrm{m}$. The BF length has been reduced during injection moulding. It can be observed that BF have high tendencies of pull-out phenomena, which is related to the construction of fibres. Although residual matrix can be observed on both the BF and WF surfaces, it indicates that the fibres had fairly good adhesion to the matrix. Also visible is the separation effect with the matrix, WF due to the large surfaces detaches from the polymer leave a trace, while the BF slides and leave the regular shape of the cylinder.
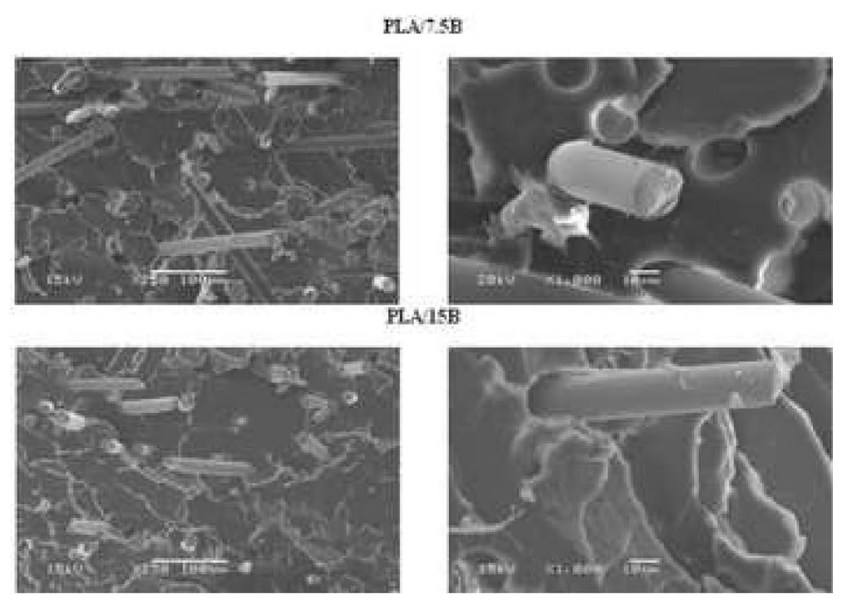

Fig. 1 Microstructure of composites with $7.5 \mathrm{wt} \%$ or $15 \mathrm{wt} \%$ of WF or BF 


\section{Thermal Analysis}

\section{Dimensional Stability}

One of the parameters that characterise the thermal properties of polymer composites is CTE. This parameter describes the thermal stability, which is very important for the materials used in engineering applications. Low thermal stability results in faster destruction of materials due to wrapping and shape changes that occur during use. For neat PLA and its composites, CTE was in the range of -30 to $70{ }^{\circ} \mathrm{C}$ (Fig. 2). The addition of both WF and BF was found to lower the coefficient values. A decrease in CTE values was shown to be most likely associated with a low coefficient of linear expansion in the case of cellulose $\left(1.4 \times 10^{-7}{ }^{\circ} \mathrm{C}^{-1}\right)$ and basalt $\left(3.6-9.7 \times 10^{-6}{ }^{\circ} \mathrm{C}^{-1}\right)[20,21]$. The lowest values were recorded for PLA/15B $\left(36.9 \times 10^{-6} \mathrm{~K}^{-1}\right)$, compared to neat PLA for which a decrease of $53 \%$ was noted

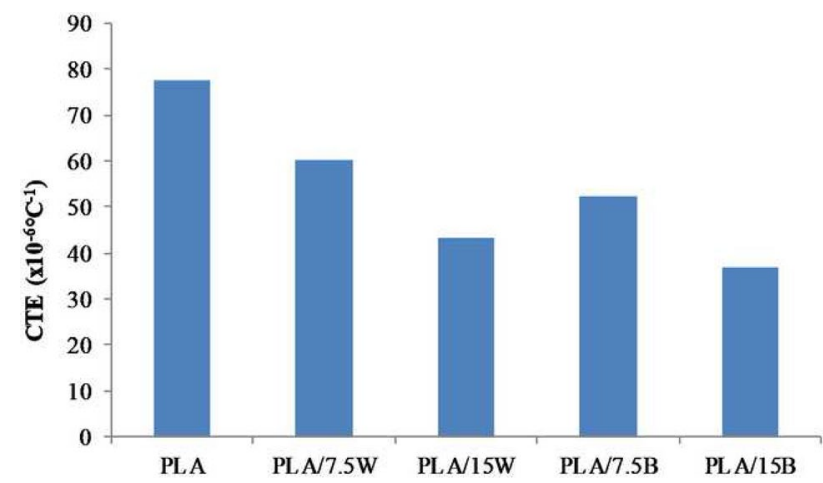

Fig. 2 Coefficient of thermal expansion of neat PLA and its composites $\left(77.7 \times 10^{-6}{ }^{\circ} \mathrm{C}^{-1}\right)$. The positive effect of natural fillers on CTE has been widely described in the literature [13, 22].

\section{Melting Behaviour and Crystallisation}

Due to low glass transition temperatures $\left(\mathrm{T}_{\mathrm{g}}\right)$ and slow crystallisation, the possibility of using PLA as an engineering material is very limited. Even during injection moulding, in which a slight cold crystallisation occurs in the cooling period, PLA remains more amorphous. Therefore, additives (e.g. talc) are often added to amorphous polymers for accelerating or initiating the crystallisation process [23].

In this study, all the tested composites showed a glass transition effect, as well as a relaxation effect on the enthalpy of cold crystallisation, recrystallisation, melting and crystallisation. The corresponding results are presented in Table 1, and the data are plotted in Fig. 3. According to the results, the addition of fillers did not affect the $\mathrm{T}_{\mathrm{g}}$ values of the tested composites, and their introduction did not contribute to the relaxation of the PLA chain segments, mainly due to the size of the fibres, which were much larger than the PLA chain segments. These findings have also been confirmed in previous works [24]. In addition, in the case of pure PLA and its $\mathrm{BF}$ composites, no effects of cold crystallisation were visible during cooling, which indicated that the material used in the tests was difficult to crystallise. On the other hand, in the composites with WF, the crystallisation effect was visible even with the content of $7.5 \mathrm{wt} \%$, and in the case of PLA $/ 15 \mathrm{~W} \Delta \mathrm{H}_{\mathrm{cc}}$ was $17.51 \mathrm{~J} / \mathrm{g}$, while for pure PLA the value was $0.62 \mathrm{~J} / \mathrm{g}$ during the first cooling cycle (Table 1).

The addition of fibres caused the temperature of cold crystallisation $\left(\mathrm{T}_{\mathrm{cc}}\right)$ to reduce compared to neat PLA. Moreover, with the increase in fibre content, $\mathrm{T}_{\mathrm{cc}}$ decreased, with the lowest values recorded for PLA/15W. The introduction

Table 1 Temperatures of glass transition $\left(\mathrm{T}_{\mathrm{g}}\right)$, cold crystallization $\left(\mathrm{T}_{\mathrm{cc}}\right)$, melting $\left(\mathrm{T}_{\mathrm{m}}\right)$, crystallization $\left(\mathrm{T}_{\mathrm{c}}\right)$ and results of cold crystallization enthalpy $\left(\Delta \mathrm{H}_{\mathrm{cc}}\right)$, melting enthalpy $\left(\Delta \mathrm{H}_{\mathrm{m}}\right)$, crystallization enthalpy after 1st and 2 nd heating cycle

\begin{tabular}{|c|c|c|c|c|c|c|c|c|}
\hline \multirow[t]{2}{*}{ Description of samples } & \multicolumn{2}{|l|}{$\mathrm{T}_{\mathrm{g}}\left({ }^{\circ} \mathrm{C}\right)$} & \multicolumn{2}{|l|}{$\mathrm{T}_{\mathrm{cc}}\left({ }^{\circ} \mathrm{C}\right)$} & \multicolumn{2}{|l|}{$\mathrm{T}_{\mathrm{m}}\left({ }^{\circ} \mathrm{C}\right)$} & \multicolumn{2}{|l|}{$\mathrm{T}_{\mathrm{c}}\left({ }^{\circ} \mathrm{C}\right)$} \\
\hline & 1st heating & 2nd heating & 1st heating & 2nd heating & 1st heating & 2nd heating & 1st heating & 2nd heating \\
\hline PLA & 60 & 60 & 99 & 103 & 180 & 177 & 99 & 98 \\
\hline PLA/7.5W & 61 & 60 & 90 & 92 & 180 & 177 & 100 & 96 \\
\hline PLA/15W & 61 & 60 & 89 & 91 & 178 & 178 & 101 & 94 \\
\hline PLA/7.5B & 61 & 60 & 95 & 97 & 180 & 176 & 99 & 97 \\
\hline \multirow[t]{2}{*}{ PLA/15B } & 62 & 60 & 94 & 96 & 180 & 178 & 97 & 95 \\
\hline & \multicolumn{2}{|l|}{$\Delta \mathrm{H}_{\mathrm{cc}}(\mathrm{J} / \mathrm{g})$} & \multicolumn{2}{|l|}{$\Delta \mathrm{H}_{\mathrm{m}}(\mathrm{J} / \mathrm{g})$} & \multicolumn{2}{|l|}{$\Delta \mathrm{H}_{\mathrm{c}}(\mathrm{J} / \mathrm{g})$} & \multicolumn{2}{|l|}{$\mathrm{X}_{\mathrm{c}}(\%)$} \\
\hline PLA & 30.47 & 29.14 & 43.31 & 44.34 & 4.68 & 0.62 & 13.80 & 16.34 \\
\hline PLA/7.5W & 25.92 & 18.36 & 41.25 & 42.76 & 10.34 & 1.31 & 16.65 & 26.50 \\
\hline PLA/15W & 19.38 & 7.01 & 34.44 & 36.00 & 17.51 & 3.43 & 16.34 & 31.46 \\
\hline PLA/7.5B & 27.55 & 23.60 & 40.64 & 40.51 & 5.91 & 0.46 & 14.22 & 18.37 \\
\hline PLA/15B & 20.15 & 21.01 & 32.35 & 33.53 & 4.36 & 0.24 & 13.24 & 13.59 \\
\hline
\end{tabular}




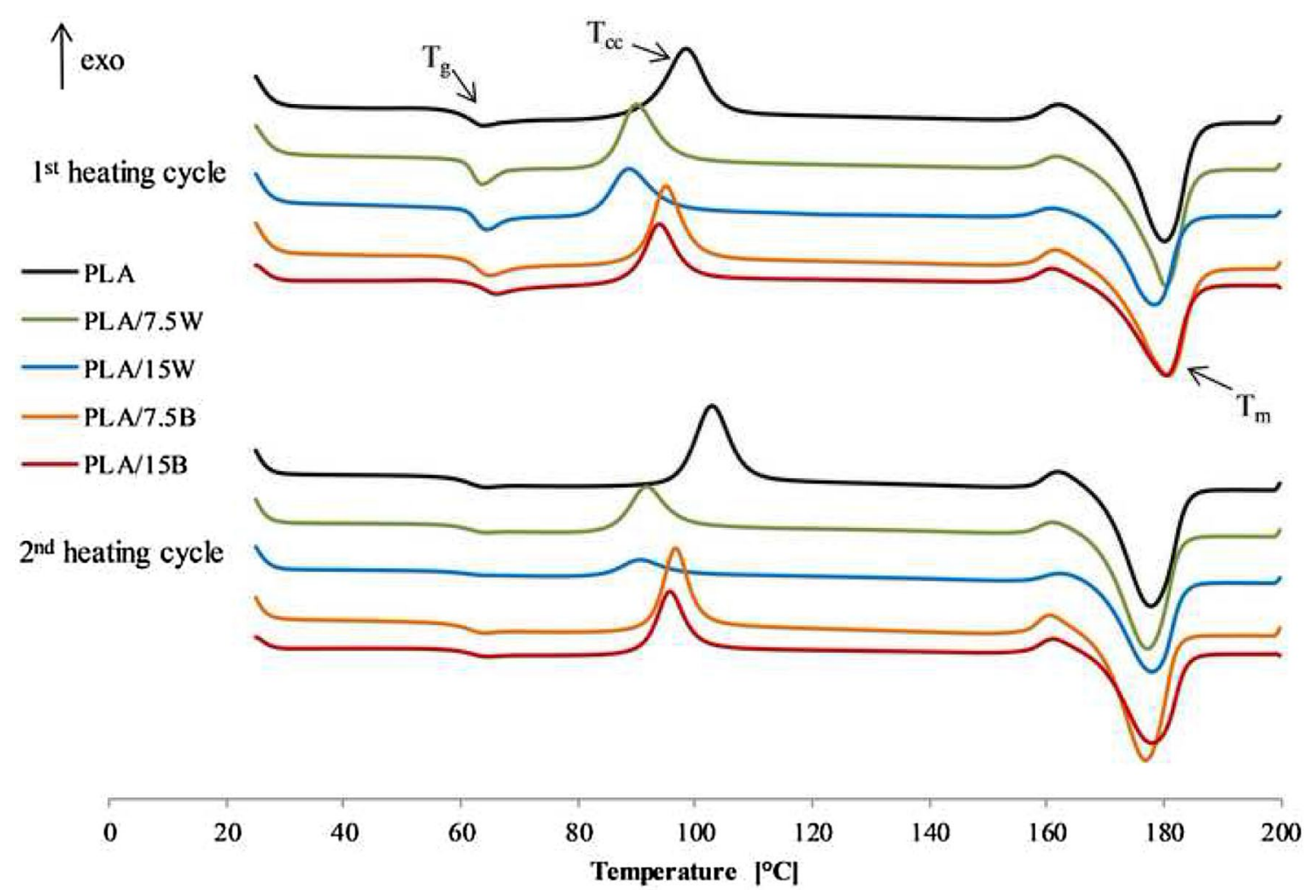

Fig. 3 DSC curves of PLA and its composites recorded from 1st and 2nd heating scans

of fibres had an effect on the reduction of energy production during the crystallisation process, and the lowest energy was released by the composites with $15 \mathrm{wt} \%$ of WF after the second heating cycle $(7.01 \mathrm{~J} / \mathrm{g})$. The crystallinity transformation occurred faster in composites than pure PLA, and the earliest transformation was observed in PLA/ $15 \mathrm{~W}\left(74^{\circ} \mathrm{C}\right)$. This effect was associated with the role played by fibres as nucleating agent, which allowed initiating the transformation. The nucleation effect of natural fibres has been increasingly described in the literature [25]. Similar relations have been reported in the work of Ying, which confirmed that the introduction of $\mathrm{BF}$ can promote the cold crystallisation of the matrix PLA [26]. The addition of fibres also affected the increase of the degree of crystallinity $\left(X_{\mathrm{c}}\right)$ of PLA composites, which was confirmed by strength tests-with the increase in crystallinity, the stiffness of materials increased. The neat polymer had strong bonds between the chains, whereas the introduction of the filler increased the chance of bond breaking, which enabled the easier formation of crystals [27]. In addition, it is possible that the increase in crystallinity was due to the increased availability of nucleation sites, which could led to faster transcrystallinity and formation of spherulites [28]. However, a deeper analysis of the molecular structure is needed to confirm this statement.

The highest degree of crystallinity was noted for WF composites $(31.46 \%)$ after the second heating cycle. This effect was associated with a much higher specific surface area of WFs compared to BFs, which had much smaller fibre diameters, as confirmed by the fractographic analysis.

\section{Mechanical Properties}

The data on density, un-notched impact strength and VST recorded during the tests at room temperature are presented in Table 2. It was observed that the density of composites with WF did not change significantly (approximately $2 \%$, $0.01-0.03 \mathrm{~g} / \mathrm{cm}^{3}$ ). These results were confirmed by other researchers in their study on polymer composites prepared with lignocellulose additives [19]. However, the increase in density of composites with BF ranged from 4\% (PLA/7.5B) up to $8.8 \%$ (PLA/15B). This effect was related to the high density of $\mathrm{BF}\left(2.67 \mathrm{~g} / \mathrm{cm}^{3}\right)$ introduced into the PLA matrix $\left(1.24 \mathrm{~g} / \mathrm{cm}^{3}\right)$.

Due to the fact that PLA is classified as brittle at room temperature, it is extremely important to increase its impact strength. It is known that low impact strength is a result of weak interfacial adhesion between fibre and matrix, which causes debonding, pull-out, fracture of the fibre and strain resistance $[29,30]$. The addition of lignocellulose fibres has been found to cause a decrease in impact strength, and the negative effect of natural fillers has also been described in the literature [27, 28]. However, 
Table 2 Density $(\rho)$, Charpy impact strength $\left(\mathrm{a}_{\mathrm{cU}}\right)$ and Vicat softening temperature (VST) for neat PLA and its biocomposites

\begin{tabular}{lllll}
\hline Description of samples & Composition & $\rho\left(\mathrm{g} / \mathrm{cm}^{3}\right)$ & $\mathrm{a}_{\mathrm{cU}}\left(\mathrm{kJ} / \mathrm{m}^{2}\right)$ & $\mathrm{VST}\left({ }^{\circ} \mathrm{C}\right)$ \\
\hline PLA & $\begin{array}{l}\text { Polylactide } \\
\text { Nature Plast PLI003 }\end{array}$ & $1.25 \pm 0.02$ & $20.4 \pm 0.3$ & $60.8 \pm 0.2$ \\
PLA/7.5W & $\begin{array}{l}\text { Polylactide }+7.5 \mathrm{wt} \% \\
\text { wood fibres }\end{array}$ & $1.26 \pm 0.06$ & $13.4 \pm 0.2$ & $68.4 \pm 0.1$ \\
PLA/15W & $\begin{array}{l}\text { Polylactide }+15 \mathrm{wt} \% \\
\text { wood fibres }\end{array}$ & $1.28 \pm 0.01$ & $14.1 \pm 0.2$ & $70.5 \pm 0.1$ \\
PLA/7.5B & $\begin{array}{l}\text { Polylactide }+7.5 \mathrm{wt} \% \\
\text { basalt fibres } \\
\text { PLA/15B }\end{array}$ & $1.30 \pm 0.02$ & $24.1 \pm 0.3$ & $69.5 \pm 0.2$ \\
& $\begin{array}{l}\text { Polylactide }+15 \mathrm{wt} \% \\
\text { basalt fibres }\end{array}$ & $1.36 \pm 0.04$ & $27.8 \pm 0.4$ & $72.5 \pm 0.5$ \\
\hline
\end{tabular}

the addition of other natural fibres such as BFs caused an increase in impact strength, and in the composites prepared with $15 \mathrm{wt} \%$ filler an increase from 20.44 to $27.76 \mathrm{~kJ} / \mathrm{m}^{2}$ was recorded. These results of impact strength were confirmed by the analysis of elongation at break, in which lower values were found for the composites with WF $(2.5 \%$-PLA/7.5WF and $2.11 \%-\mathrm{PLA} / 15 \mathrm{WF})$ compared to the composites with $\mathrm{BF}(3.17 \%-\mathrm{PLA} / 7.5 \mathrm{BF}$ and $2.74 \%-\mathrm{PLA} / 15 \mathrm{BF})$. In the case of BF composites, the elongation at break decreased with an increase in the number of fibres; however, due to the high impact-resistant properties of $\mathrm{BF}$, the impact strength values were found to be increased.

Due to the low $\mathrm{T}_{\mathrm{g}}$ of PLA, the products made of this material have a low thermal resistance, which significantly reduces their use. In order to increase the thermal resistance of these composites, two approaches are mainly used: increasing $\mathrm{T}_{\mathrm{g}}$ or crystallinity and achieving reinforcement of composites using a filler. Research shows that the incorporation of fibres the into matrix improves the heat resistance of composites [31]. In this study, VST was observed to be higher for all the composites compared to neat PLA, and the higher the content of fibres the higher the VST was. The highest improvement in VST was observed for PLA/15B $\left(-72.5 \pm 0.5^{\circ} \mathrm{C}\right)$. Similar results were obtained for PLA/15W $\left(70.5 \pm 0.1{ }^{\circ} \mathrm{C}\right)$ and PLA/7.5B $\left(69.5 \pm 0.2{ }^{\circ} \mathrm{C}\right)$. The improvement of thermal resistance of composites through the introduction of fibres was related to the reduction of the movements of the molecular chain, which caused the deformation of composites. Composites with BF had a higher VST than those with WF because BF composites had higher strength, as described in the later part of this paper, and additionally, BF was much more resistant to temperatures than WF. Furthermore, the fibres acted like a nucleating agent and improved the $\mathrm{T}_{\mathrm{g}}$ values (from $60{ }^{\circ} \mathrm{C}$ (PLA) up to $\left.64{ }^{\circ} \mathrm{C}(\mathrm{PLA} / 15 \mathrm{~B})\right)$, which also had a positive effect on the VST results.

\section{Tensile Properties}

Figure 4 shows the results of tensile test (a: tensile strength, b: modulus of elasticity and c: strain at break) recorded at various temperatures $\left(-24,23\right.$ and $\left.+80{ }^{\circ} \mathrm{C}\right)$. No improvement was observed in tensile strength in PLA/WF composites due to the lack of good adhesion of the fibres to the matrix. The addition of WF caused a decrease in tensile strength, and the values decreased by about $19 \%$ and $25 \%$ in the case of PLA/7.5WF and PLA/15WF, respectively, at room temperature. This effect was mainly related to the hydrophobic nature of the PLA surface and the hydrophilic nature of WF. Many studies suggest that the addition of coupling agent or surface treatment of fibres may improve the fibre-matrix adhesion in polymer-wood composites [32]. The addition of WF was found to be more effective in improving the modulus of the composites than the tensile strength. For composites with $15 \mathrm{wt} \% \mathrm{WF}$, Young's modulus improved by $45 \%$ (from 4.2 to $6.1 \mathrm{GPa}$ ). The reinforcement capability of wood fillers has been studied in various PLA composites so far [33].

The addition of BF significantly improved both tensile strength and Young's modulus. As the fibre content increased, the values of these parameters increased. This effect was independent of the applied test temperature. The increase in tensile strength observed in PLA/7.5B was $3.2 \%$ (from 92.73 to $95.94 \mathrm{MPa}$ ), while in PLA/15B, it was $13 \%$ (from 92.73 to $105.09 \mathrm{MPa}$ ), in comparison to the neat PLA investigated at $-24{ }^{\circ} \mathrm{C}$. At room temperature, this effect was lower and the increase was from $67.75 \mathrm{MPa}$ (neat PLA) up to 69.1 and 72.14 MPa for PLA/7.5B and PLA/15B, respectively. The addition of $15 \mathrm{wt} \%$ basalt improved the stiffness of composites by as much as $86 \%$ (from 4.2 to $7.8 \mathrm{GPa}$ ). Composites with $15 \mathrm{wt} \% \mathrm{WF}$ and $7.5 \mathrm{wt} \% \mathrm{BF}$ showed a similar gain in the value by over $40 \%$. The differences observed between the values of Young's modulus at room temperature and at $-24{ }^{\circ} \mathrm{C}$ were insignificant (about 5\%). 
A

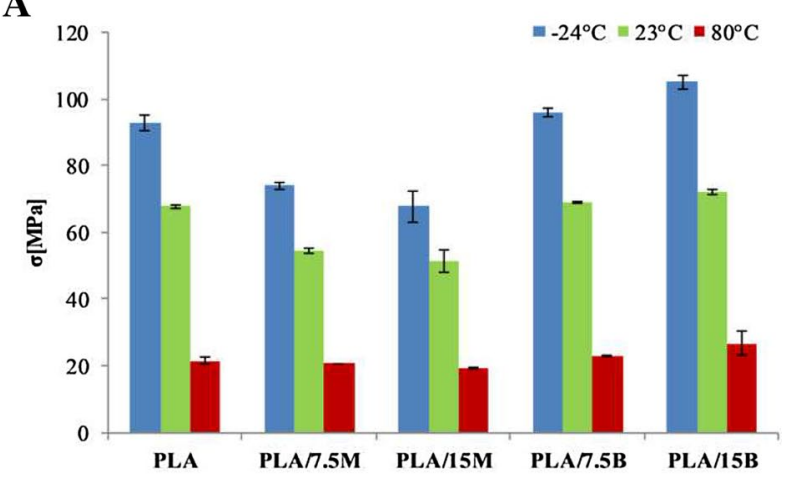

B

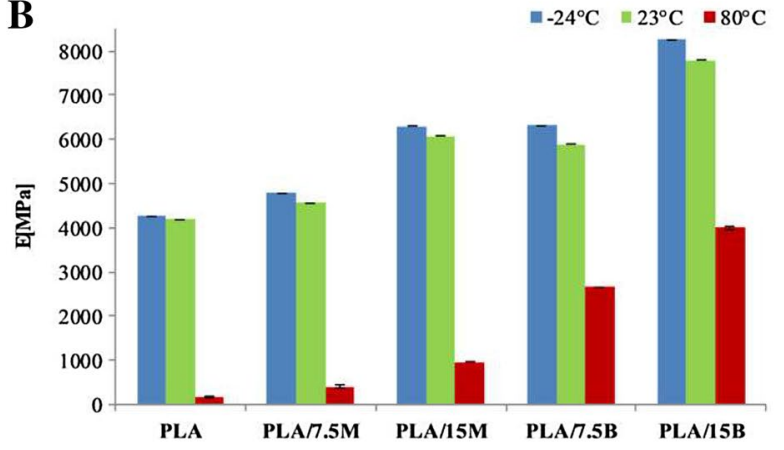

C

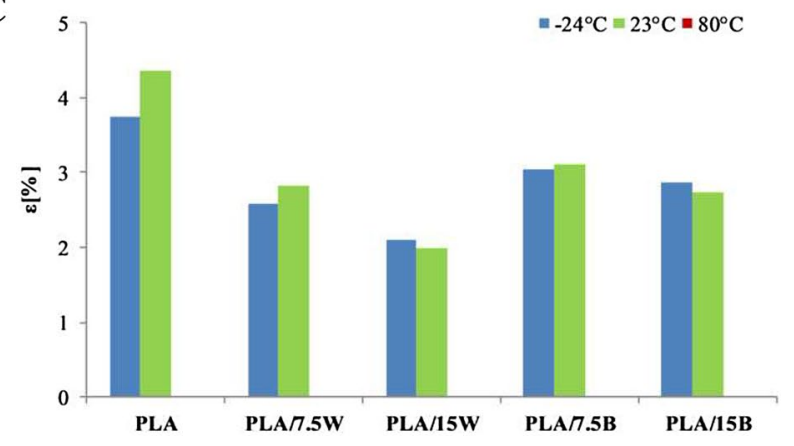

Fig. 4 Comparison of tensile strength (a), Young modulus (b) and strain at break (c) of neat PLA and its composites at various temperatures

The lowest values were noted for the composites tested at $80{ }^{\circ} \mathrm{C}$, with tensile strength in the range of $19.16 \mathrm{MPa}$ (PLA/15 W) to 26.64 (PLA/15B). The mechanical properties were poor at reduced temperatures, due to the low glass transition temperature of PLA $\left(60^{\circ} \mathrm{C}\right)$ [34]. A high (almost 90\%) decrease in stiffness was observed for neat PLA and WF composites.

As the content of fibres increased, elongation decreased. Composites containing BFs had higher elongation values than WF, which was most likely due to the sliding of the BF [35]. The pull-out phenomenon was clearly seen in the case of BF, which was confirmed by the SEM observations. The results could not be determined at $80^{\circ} \mathrm{C}$ because the values exceeded the scale of the machine ( $>20 \%)$.

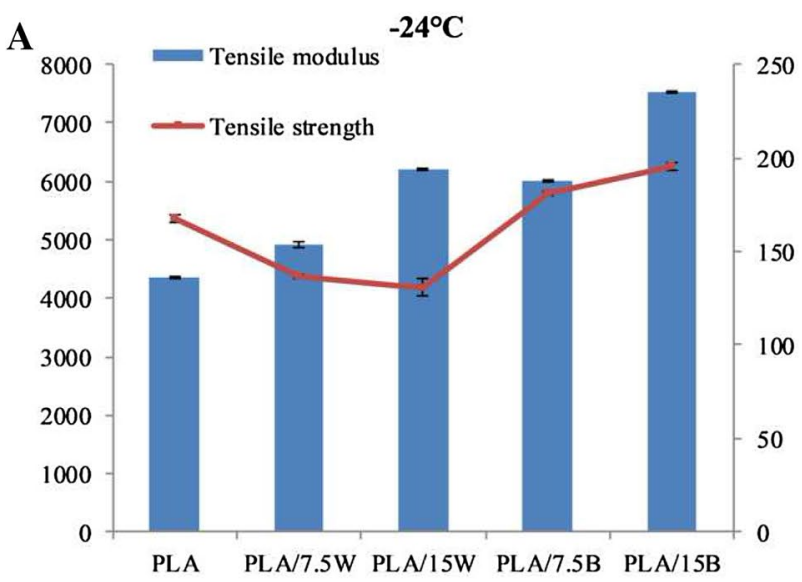

B

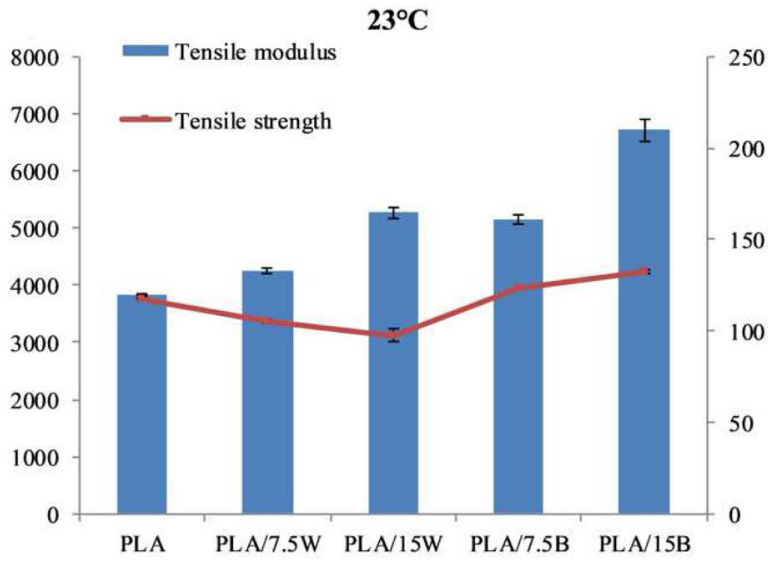

C

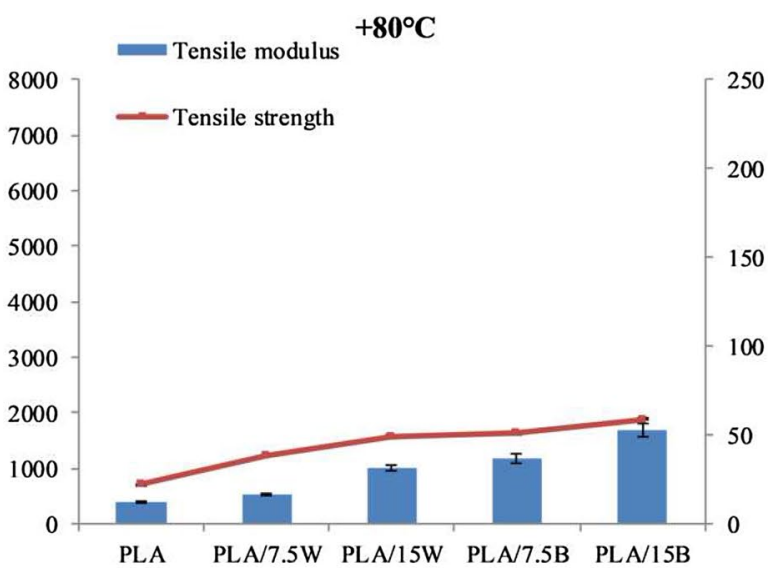

Fig. 5 Bending properties of PLA and its composites tested at various temperature: $-24{ }^{\circ} \mathrm{C},+23{ }^{\circ} \mathrm{C}$, and $+80{ }^{\circ} \mathrm{C}$

\section{Flexural Properties}

The results of the three-point bending test of neat PLA and its composites carried out at various temperatures are shown in Fig. 5. Similar relationships as in the case of tensile properties were observed for bending properties. In the case of 
PLA/7.5 W and PLA/15 W composites, the addition of WF caused a decrease in the value of flexural strength by $10 \%$ and $17 \%$ and improvement of flexural modulus by $11 \%$ and $38 \%$, respectively, at room temperature. It was observed that at all temperatures, the value of flexural modulus increased with an increase in the content of fibres. Moreover, no significant change was observed in the flexural modulus of PLA15/W or PLA/7.5B at any of the studied temperatures. The negative effect of the addition of lignocellulosic fibres on flexural strength has already been described in the literature [36-38].

However, a much higher increase of bending strength was observed at elevated temperatures, at which the bending strength of the composites with $15 \%$ BFs increased three fold compared to the value of neat PLA. Additionally, for composites with WF, the flexural strength significantly improved by more than twofold (PLA-21.9 \pm 0.8 and $\mathrm{PLA} / 15 \mathrm{~W}-48.6 \pm 1.0)$ at elevated temperatures.

\section{Hydrolytic Degradation}

\section{Water Uptake}

Figure 6 shows the percentage of the mass changes observed in neat PLA and its composites. The composites were soaked in water at a temperature of $40 \pm 3{ }^{\circ} \mathrm{C}$ and in saline solution because such composites are anticipated to be used in diagnostic equipment (single use) and as rehabilitation products. It was noted that the addition of fillers containing lignocellulose significantly increased the ability of the composites to absorb water. This effect is well known and associated with the composition of fibres, which consists of hydroscopic substances, such as carbohydrates and lignin, that lead to water uptake [38]. The more the addition of

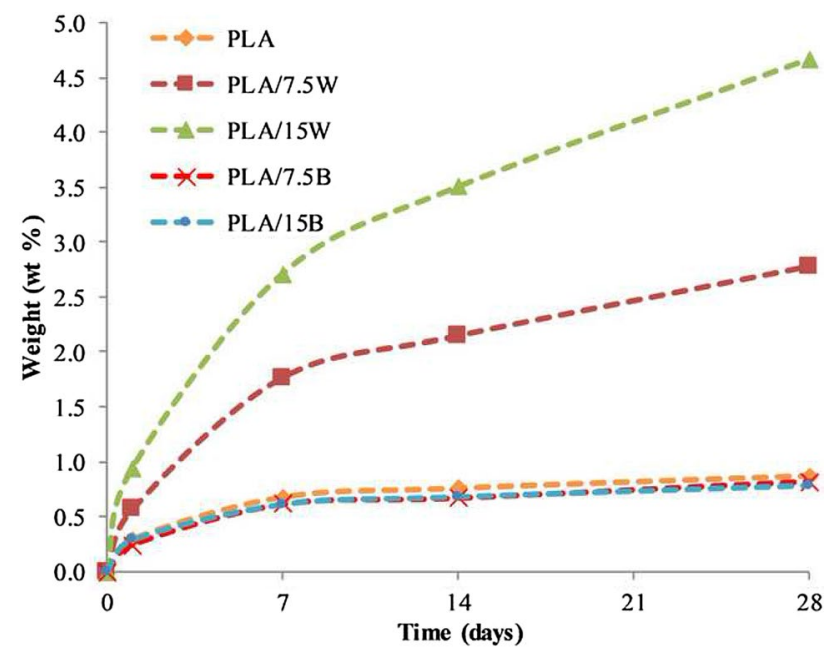

Fig. 6 Weight gain of neat PLA and its composites immersed in saline solution at $40^{\circ} \mathrm{C}$ fibres, the higher the water sorption, and after 28 days the mass of PLA $/ 15 \mathrm{~W}$ increased by $4.7 \mathrm{wt} \%$. Regardless of the type of additive added to PLA, together with the increase in the time of incubation in water, an increase in the mass of the samples was noted. This effect was more intense in WF than BF; composites with BF had a similar mass at all incubation times, and after 28 days, gained only approximately $0.6 \mathrm{wt} \%$. This result indicates a low ability of BF to absorb water, which is confirmed in other studies as well [39]. In comparison with WF, in which the level of absorbed water increased with an increase in filler content, BFs had several times lower water-absorbing capacity and were stable throughout the whole immersion period. Moreover, in BF the water saturation point was reached after 7 days, but in the case of WF, the saturation point was not reached even after 28 days. Composites with BF reached the saturation point faster and showed stabilised absorption of water compared to composites with WF. This was due to the swelling of lignocellulose fibres that led to the cracking of matrix and the formation of microchannels through which water could further penetrate the sample.

\section{Thermal and Mechanical Properties of Treated Composites}

The effect of the process of biodegradation on the mechanical properties of composites is shown in Fig. 7. A decrease in mechanical properties was seen for all the materials during the tensile test which was insignificant and determined as only about 5\%. According to the DSC results, after 4 weeks of incubation the crystallinity of composites was higher than that before degradation (Table 3). Although the literature has described the positive effect of the increase in crystallinity on the increase of mechanical properties, the parameters were found to have reduced values despite the increase in crystallinity in the present study. This was related to the occurrence of degradation and cracking of polymer chains. The highest decreases were recorded for tensile strength and Young's modulus in neat PLA and composites with 15 wt $\%$ WF. For pure PLA, higher decreases were noted due to the fact that the degradation proceeded mainly in amorphous areas. On the other hand, due to the introduction of lignocellulosic fibres into the matrix, when the composites were soaked in water, the fibres absorbed water and swelled, which additionally contributed to the creation of internal stresses. By contrast, non-water-absorbing BF reduced the possibility of stress formation due to dimensional stability. The hydrolytic process of degradation caused a decrease in the strain at break [40].

Table 4 presents the results of the DSC thermal analysis of samples after 28 days of incubation in water. Comparing the results with those obtained for untreated materials, it can be concluded that hydrolytic degradation increased $\mathrm{T}_{\mathrm{g}}$ and decreased $\mathrm{T}_{\mathrm{cc}}$ and its enthalpy. The reduction in $\mathrm{T}_{\mathrm{cc}}$ 
A

$$
\text { Tensile strength }[\mathrm{MPa}]
$$

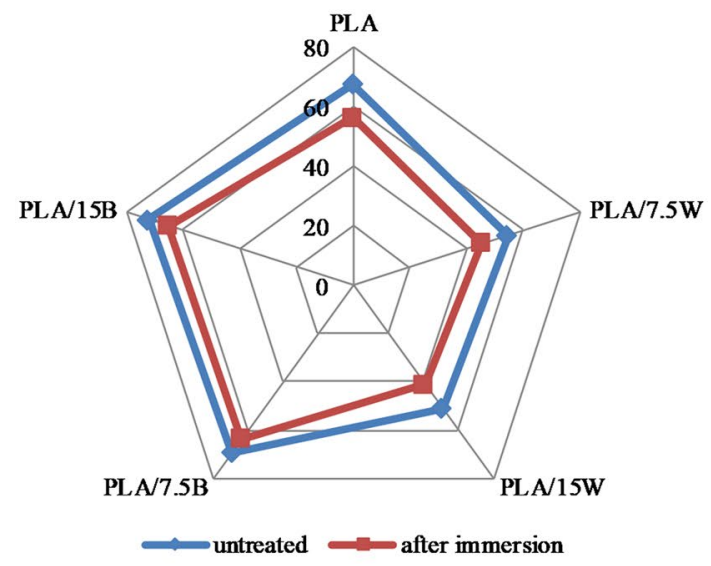

B

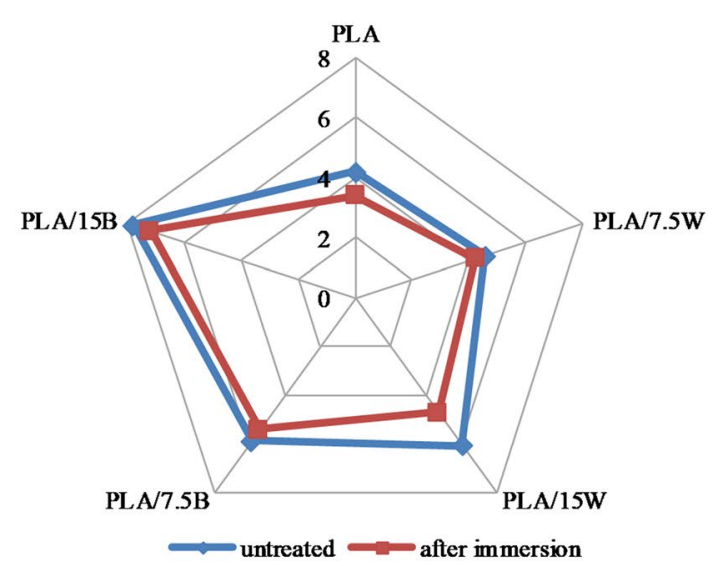

C

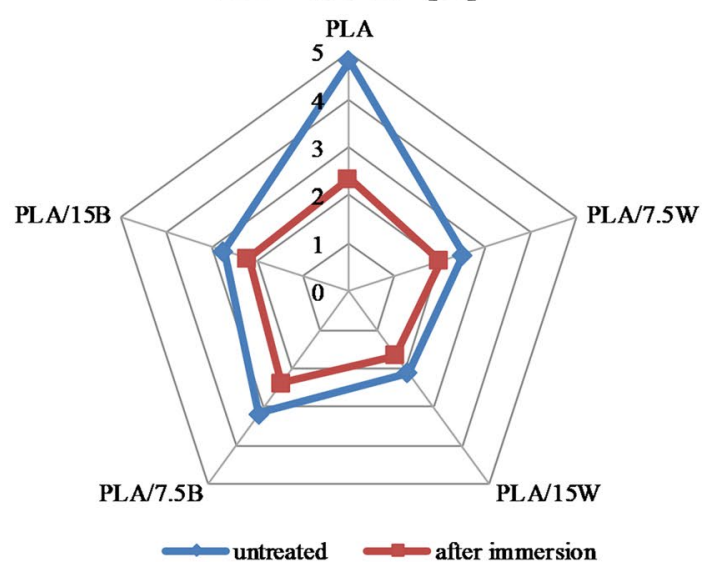

Fig. 7 Mechanical properties of PLA and its composites after injection moulding and after 4 weeks immersion in water observed after hydrolysis was caused by a decrease in the molecular weight of PLA, which rendered the polymer chains with a greater ability to move and create new crystals. After the second heating cycle, there was an increase in $T_{c c}$ noted in the treated samples, and the differences were higher than that of the untreated materials. Materials subjected to hydrolytic degradation showed a higher degree of crystallinity than after injection. This phenomenon was related to the first stage of degradation involving the splitting of the hydrolytic chain with the diffusion of water, which moved in the amorphous regions [41]. The increase in the crystallinity of polymers after the hydrolytic degradation process has also been reported [42]. Higher crystallinity values were noted for composites, as also confirmed by mechanical tests, because with the increase in crystallinity, the mechanical properties of the tested materials increased [43].

\section{Conclusion}

The results of the present research showed that the rate of biodegradation can be controlled and strength properties of PLA composites can be changed by choosing the right type and amount of fibre. Natural fibres and renewable raw materials of high rigidity and relatively fast biodegradability can be used for making biodegradable composites that are advantageous when used as disposable products. This study showed that the addition of WF and BF significantly improved the tensile and flexural modulus of the composites, confirming the reinforcing effect of both types of fibres. These parameters increased as the fibre content increased, and the highest values were recorded for PLA/15B composite where improvement was $85 \%$ for Young Modulus. Despite the slight increase in density, the increase in the strength and impact properties of the composites with BF was significant and the neat PLA's density $1.25 \mathrm{~g} / \mathrm{cm}^{3}$ and $\mathrm{a}_{\mathrm{cU}} 20.4 \mathrm{~kJ} / \mathrm{m}^{2}$ while for PLA/15B the density was $1.36 \mathrm{~g} /$ $\mathrm{cm}^{3}$ and $\mathrm{a}_{\mathrm{cU}} 27.8 \mathrm{~kJ} / \mathrm{m}^{2}$. Mechanical properties were confirmed by DSC results, which showed an increase in $\mathrm{X}_{\mathrm{c}}$ from $16.34 \%$ (PLA) up $31.46 \%$ (PLA/15 W) and a decrease in $\mathrm{T}_{\mathrm{cc}}$ from $103{ }^{\circ} \mathrm{C}$ (PLA) to $91{ }^{\circ} \mathrm{C}$ (PLA/15 W). In addition, the fillers had a positive effect on the thermal properties of composites (VST and CTE) which makes the produced materials attractive for technical and medical applications and the improvement was about $20 \%$ and $50 \%$ for VST and CTE, respectively.

The work allowed demonstrating the differences in the biodegradation process of composites prepared with fibres of various origins. The addition of WFs rapidly increased both water uptake and the process of hydrolytic degradation in saline solution, whereas BFs, which are non-water-absorbing fibres, did not affect the water uptake process and therefore were saturated with water after 14 days. A slight decrease in 
Table 3 Comparison of the degree of crystallinity $\left(\mathrm{X}_{\mathrm{c}}\right)$ for samples after injection and treated samples

\begin{tabular}{llllll}
\hline Material & \multicolumn{3}{l}{$X_{\mathrm{c}}(\%)$} & & \\
\cline { 2 - 3 } & 1st heating & & & & \\
\cline { 2 - 3 } & After injection & After immersion & & After injection & After immersion \\
\hline PLA & 13.80 & 19.30 & 16.34 & 20.80 \\
PLA/7.5 W & 16.65 & 24.18 & 26.50 & 31.70 \\
PLA/15 W & 16.34 & 22.67 & 31.46 & 38.85 \\
PLA/7.5B & 14.22 & 18.35 & 18.37 & 23.94 \\
PLA/15B & 13.24 & 19.27 & 13.59 & 21.77 \\
\hline
\end{tabular}

Table 4 Temperatures of glass transition $\left(\mathrm{T}_{\mathrm{g}}\right)$, cold crystallization $\left(\mathrm{T}_{\mathrm{cc}}\right)$, melting $\left(\mathrm{T}_{\mathrm{m}}\right)$, crystallization $\left(\mathrm{T}_{\mathrm{c}}\right)$ after $1 \mathrm{st}$ and 2 nd heating cycle for treated samples

\begin{tabular}{|c|c|c|c|c|c|c|c|c|}
\hline \multirow[t]{2}{*}{ Material } & \multicolumn{2}{|l|}{$\mathrm{T}_{\mathrm{g}}\left({ }^{\circ} \mathrm{C}\right)$} & \multicolumn{2}{|l|}{$\mathrm{T}_{\mathrm{cc}}\left({ }^{\circ} \mathrm{C}\right)$} & \multicolumn{2}{|l|}{$\mathrm{T}_{\mathrm{m}}\left({ }^{\circ} \mathrm{C}\right)$} & \multicolumn{2}{|l|}{$\mathrm{T}_{\mathrm{c}}\left({ }^{\circ} \mathrm{C}\right)$} \\
\hline & 1st heating & $\overline{2 \text { nd heating }}$ & 1st heating & 2nd heating & 1st heating & 2nd heating & 1 st heating & 2nd heating \\
\hline PLA & 62 & 59 & 91 & 100 & 177 & 175 & 101 & 101 \\
\hline PLA/7.5W & 61 & 59 & 86 & 90 & 179 & 176 & 100 & 96 \\
\hline PLA/15W & 63 & 59 & 90 & 89 & 180 & 176 & 102 & 97 \\
\hline PLA/7.5B & 61 & 59 & 88 & 95 & $176 / 179$ & 175 & 100 & 99 \\
\hline PLA/15B & 64 & 59 & 91 & 94 & $177 / 179$ & 176 & 99 & 99 \\
\hline
\end{tabular}

the mechanical properties of the samples was observed after biodegradation. As shown by the results of mechanical tests of the composites subject to biodegradation, these composites can be successfully used for making products with longterm application, without significant reduction in strength.

All authors contributed to the study conception and design. Material preparation, data collection and analysis were performed by Stanisław Kuciel, Karolina Mazur and Marek Hebda. The first draft of the manuscript was written by Karolina Mazur and all authors commented on previous versions of the manuscript. All authors read and approved the final manuscript.

Open Access This article is licensed under a Creative Commons Attribution 4.0 International License, which permits use, sharing, adaptation, distribution and reproduction in any medium or format, as long as you give appropriate credit to the original author(s) and the source, provide a link to the Creative Commons licence, and indicate if changes were made. The images or other third party material in this article are included in the article's Creative Commons licence, unless indicated otherwise in a credit line to the material. If material is not included in the article's Creative Commons licence and your intended use is not permitted by statutory regulation or exceeds the permitted use, you will need to obtain permission directly from the copyright holder. To view a copy of this licence, visit http://creativecommons.org/licenses/by/4.0/.

\section{References}

1. Okunola AA, Kehinde IO, Oluwaseun A, Olufiropo EA (2019) Public and environmental health effects of plastic wastes disposal: a Review. J Toxicol Risk Assess. https://doi.org/10.23937/25724061.1510021

2. Castro-Aguirre E, Iñiguez-Franco F, Samsudin $\mathrm{H}$ et al (2016) Poly(lactic acid) — mass production, processing, industrial applications, and end of life. Adv Drug Deliv Rev 107:333-366. https ://doi.org/10.1016/j.addr.2016.03.010

3. Feng L, Bian X, Li G et al (2016) Compatibility, mechanical properties and stability of blends of polylactide and polyurethane based on poly(ethylene glycol)-b-polylactide copolymers by chain extension with diisocyanate. Polym Degrad Stab 125:148-155. https://doi.org/10.1016/j.polymdegradstab.2015.12.017

4. Farah S, Anderson DG, Langer R (2016) Physical and mechanical properties of PLA, and their functions in widespread applications-a comprehensive review. Adv Drug Deliv Rev 107:367392. https://doi.org/10.1016/j.addr.2016.06.012

5. Akindoyo JO, Beg MDH, Ghazali S et al (2018) Impact modified PLA-hydroxyapatite composites-thermo-mechanical properties. Compos A 107:326-333. https://doi.org/10.1016/j.composites a.2018.01.017

6. Notta-Cuvier D, Odent J, Delille R et al (2014) Tailoring polylactide (PLA) properties for automotive applications: effect of addition of designed additives on main mechanical properties. Polym Test 36:1-9. https://doi.org/10.1016/j.polymertesting.2014.03.007

7. Dalu M, Temiz A, Altuntaş E et al (2019) Characterization of tanalith E treated wood flour filled polylactic acid composites. Polym Test 76:376-384. https://doi.org/10.1016/j.polymertes ting.2019.03.037

8. Xu K, Li K, Zhong T et al (2014) Effects of chitosan as biopolymer coupling agent on the thermal and rheological properties of polyvinyl chloride/wood flour composites. Compos B 58:392399. https://doi.org/10.1016/j.compositesb.2013.10.056 
9. Ansari F, Granda LA, Joffe R et al (2017) Experimental evaluation of anisotropy in injection molded polypropylene/wood fiber biocomposites. Compos A 96:147-154. https://doi.org/10.1016/j. compositesa.2017.02.003

10. Faludi G, Dora G, Renner K et al (2013) Improving interfacial adhesion in PLA/wood biocomposites. Compos Sci Technol 89:77-82. https://doi.org/10.1016/j.compscitech.2013.09.009

11. Csikós Á, Faludi G, Domján A et al (2015) Modification of interfacial adhesion with a functionalized polymer in PLA/wood composites. Eur Polym J 68:592-600. https://doi.org/10.1016/j.eurpolymj.2015.03.032

12. Espinach FX, Delgado-Aguilar M, Puig J et al (2015) Flexural properties of fully biodegradable alpha-grass fibers reinforced starch-based thermoplastics. Compos B 81:98-106. https://doi. org/10.1016/j.compositesb.2015.07.004

13. Jang KS (2018) Mechanics and rheology of basalt fiber-reinforced polycarbonate composites. Polymer (Guildf). https://doi. org/10.1016/j.polymer.2018.06.004

14. Vara Prasad V, Talupula S (2018) A review on reinforcement of Basalt and Aramid (Kevlar 129) fibers. Mater Today Proc 5:59935998. https://doi.org/10.1016/j.matpr.2017.12.202

15. Bauer F, Kempf M, Weiland F, Middendorf P (2018) Structureproperty relationships of basalt fibers for high performance applications. Compos B 145:121-128. https://doi.org/10.1016/j.compo sitesb.2018.03.028

16. Fiore V, Scalici T, Di Bella G, Valenza A (2015) A review on basalt fibre and its composites. Compos B 74:74-94. https://doi. org/10.1016/j.compositesb.2014.12.034

17. Bouzouita A (2016) Elaboration of polylactide-based materials for automotive application : study of structure-process-properties interactions Amani Bouzouita. Mech Mater

18. Song J, Liu J, Zhang $\mathrm{H}$ et al (2014) PVDF/PMMA/Basalt fiber composites: morphology, melting and crystallization, structure, mechanical properties, and heat resistance. J Appl Polym Sci 131:199-210. https://doi.org/10.1002/app.40494

19. Fischer EW, Sterzel HJ, Wegner G (1973) Investigation of the structure of solution grown crystals of lactide copolymers by means of chemical reactions. Kolloid-Zeitschrift Zeitschrift für Polym 251:980-990. https://doi.org/10.1007/BF01498927

20. Nishino T, Matsuda I, Hirao K (2004) All-cellulose composite. Macromolecules 37:7683-7687. https://doi.org/10.1021/ma049300h

21. Hewlett PC (2003) Lea's chemistry of cement and concrete. Butterworth-Heinemann, Oxford

22. Espinach FX, Boufi S, Delgado-Aguilar M et al (2018) Composites from poly(lactic acid) and bleached chemical fibres: thermal properties. Compos B 134:169-176. https://doi.org/10.1016/j. compositesb.2017.09.055

23. Battegazzore D, Bocchini S, Frache A (2011) Crystallization kinetics of poly(lactic acid)-talc composites. Express Polym Lett 5:849-858. https://doi.org/10.3144/expresspolymlett.2011.84

24. Kuciel S, Romańska P (2018) Hybrid composites of polylactide with basalt and carbon fibers and their thermal treatment. Materials (Basel). https://doi.org/10.3390/ma12010095

25. Wypych G (2016) Handbook of nucleating agents. Elsevier, Amsterdam

26. Ying Z, Wu D, Zhang M, Qiu Y (2017) Polylactide/basalt fiber composites with tailorable mechanical properties: effect of surface treatment of fibers and annealing. Compos Struct 176:1020-1027. https://doi.org/10.1016/j.compstruct.2017.06.042

27. Luo G, Li W, Liang W et al (2017) Coupling effects of glass fiber treatment and matrix modification on the interfacial microstructures and the enhanced mechanical properties of glass fiber/ polypropylene composites. Compos B 111:190-199. https://doi. org/10.1016/j.compositesb.2016.12.016

28. Quan H, Li ZM, Yang MB, Huang R (2005) On transcrystallinity in semi-crystalline polymer composites. Compos Sci Technol 65:999-1021. https://doi.org/10.1016/j.compscitech.2004.11.015
29. Karmarkar A, Chauhan SS, Modak JM, Chanda M (2007) Mechanical properties of wood-fiber reinforced polypropylene composites: effect of a novel compatibilizer with isocyanate functional group. Compos A 38:227-233. https://doi.org/10.1016/j. compositesa.2006.05.005

30. Nuthong W, Uawongsuwan P, Pivsa-Art W, Hamada H (2013) Impact property of flexible epoxy treated natural fiber reinforced PLA composites. Energy Procedia 34:839-847. https://doi. org/10.1016/j.egypro.2013.06.820

31. Tomaszewska J, Klapiszewski L, Skórczewska K et al (2017) Advanced organic-inorganic hybrid fillers as functional additives for poly (vinyl chloride). Polimery/Polymers 62:19-26. https:// doi.org/10.14314/polimery.2017.019

32. Spiridon I, Darie RN, Kangas H (2016) Influence of fiber modifications on PLA/fiber composites. Behavior to accelerated weathering. Compos B 92:19-27. https://doi.org/10.1016/j.composites b.2016.02.032

33. Peltola H, Pääkkönen E, Jetsu P, Heinemann S (2014) Wood based PLA and PP composites: effect of fibre type and matrix polymer on fibre morphology, dispersion and composite properties. Compos A 61:13-22. https://doi.org/10.1016/j.compositesa.2014.02.002

34. Cheng S, Lau K, Liu T et al (2009) Mechanical and thermal properties of chicken feather fiber/PLA green composites. Compos B 40:650-654. https://doi.org/10.1016/j.compositesb.2009.04.011

35. Awal A, Rana M, Sain M (2015) Thermorheological and mechanical properties of cellulose reinforced PLA bio-composites. Mech Mater 80:87-95. https://doi.org/10.1016/j.mechmat.2014.09.009

36. Huda MS, Drzal LT, Misra M, Mohanty AK (2006) Wood-fiberreinforced poly(lactic acid) composites: evaluation of the physicomechanical and morphological properties. J Appl Polym Sci 102:4569-4856. https://doi.org/10.1002/app.24829

37. Bledzki AK, Jaszkiewicz A (2010) Mechanical performance of biocomposites based on PLA and PHBV reinforced with natural fibres-a comparative study to pp. Compos Sci Technol 70:16871696. https://doi.org/10.1016/j.compscitech.2010.06.005

38. Gil-Castell O, Badia JD, Kittikorn T et al (2014) Hydrothermal ageing of polylactide/sisal biocomposites. Studies of water absorption behaviour and Physico-Chemical performance. Polym Degrad Stab 108:212-222. https://doi.org/10.1016/j.polymdegra dstab.2014.06.010

39. Mazur K, Kuciel S, Salasinska K (2019) Mechanical, fire, and smoke behaviour of hybrid composites based on polyamide 6 with basalt/carbon fibres. J Compos Mater 53:3979-3991. https://doi. org/10.1177/0021998319853015

40. Barczewski M, Andrzejewski J, Matykiewicz D et al (2019) Influence of accelerated weathering on mechanical and thermomechanical properties of poly(lactic acid) composites with natural waste filler. Polimery/Polymers 64:119-126. https://doi.org/10.14314/ polimery.2019.2.5

41. Cairncross RA, Becker JG, Ramaswamy S, O'Connor R (2006) Moisture sorption, transport, and hydrolytic degradation in polylactide. Appl Biochem Biotechnol 131:774-785. https://doi. org/10.1385/ABAB:131:1:774

42. Awal A, Rana M, Sain M (2015) Thermorheological and mechanical properties of cellulose reinforced PLA bio-composites. Mech Mater. https://doi.org/10.1016/j.mechmat.2014.09.009

43. Yatigala NS, Bajwa DS, Bajwa SG (2018) Compatibilization improves physico-mechanical properties of biodegradable biobased polymer composites. Compos A 107:315-325. https:// doi.org/10.1016/j.compositesa.2018.01.011

Publisher's Note Springer Nature remains neutral with regard to jurisdictional claims in published maps and institutional affiliations. 